\title{
Successful Management of Pyometra in a Labrador Retriever A Clinical Case Report
}

\author{
Gyan Singh $^{1}$, Amitkumar ${ }^{2 *}$, Neeraj Arora ${ }^{3}$ and V. Arjun ${ }^{2}$ \\ ${ }^{1}$ Department of Veterinary Clinical Complex, ${ }^{2}$ Department of Veterinary Gynaecology and \\ Obstetrics, ${ }^{3}$ Department of Veterinary Surgery and Radiology, India \\ College of Veterinary Sciences, Lala Lajpat Rai University of Veterinary and Animal \\ Sciences, Hisar-125004 (Haryana) India \\ *Corresponding author
}

A B S T R A C T

\section{Keywords}

Endometritis, Labrador retriever, Laparotomy, Ovariohysterectomy, Pyometra, Sanguinopurulent

Article Info

Accepted:

25 September 2020

Available Online:

10 October 2020

\section{Introduction}

Pyometra is the most common disease in female dogs (Frances, 2006) which mainly affects middle-aged female dogs that have not been spayed. It is caused by the response to progesterone stimulation, which leads to an increased predisposition to bacterial infection (Chotimanukul and Sirivaidyapong, 2010; Shiju et al., 2011). The bacteria isolated from the uteri of dogs with pyometra belong to diverse species; Escherichia coli is most frequently found (Hagman and Greko, 2005; Chotimanukul and Sirivaidyapong, 2010). The incidence of pyometra in dogs is approximately $24 \%$ before 10 years of age (Hagman, 2000). The clinical manifestations of canine pyometra depend on the patency of the cervix. Closed cervix pyometra is comparatively serious because of the absorption of toxins from the accumulated pus and consequent development of toxemia. In open cervix pyometra, bitches are less systemically affected than in closed cervix 
pyometra. Cystic Endometrial Hyperplasia (CEH) often precedes the disease, but can also be found in many older bitches with no signs of pyometra. Severe pyometra occasionally leads to fatal and systemic infection and infertility in some bitch. It has also been reported secondary to postpartum metritis (Brain and Jeff, 2012). Pyometra can occur at any age after the first estrus cycle and approximately at a mean age of two years. Pyometra can be treated surgically or medically. However, the decision depends on several factors such as open or closed cervix pyometra, the health status of the animal, and if the animal is intended for future breeding.

\section{Case history and observations}

Aneight-year-old Labrador retriever was admitted to the Veterinary Clinical Complex, Hisar, with a history of purulent-sanguineous vaginal discharge, vomiting, polydipsia, polyuria and anorexia.On physical examination, the dog was found to be quite normal except for vaginal discharge. Systemic broad-spectrum antibiotics in the form of Ceftriaxone were administered, but there was no improvement. Hematological examination (Table no. 1) revealed a high neutrophilic count (95\%), indicating the presence of infection. The lateral radiograph showed a dilated predominantly fluid-filled tubular structure located in the mid-abdomen below the lumbar vertebrae (Fig.1). Ultrasonographic findings revealed an enlarged uterus with convoluted, tubular horns filled with anechoic fluid giving speckled appearance (Fig.2). Hence it was diagnosed as a case of pyometra and OHE was considered the best treatment to prevent recurrence of the disease.

\section{Treatment and Discussion}

Ovariohysterectomy(OHE) was aseptically performed according to a standard procedure.
Premedication was administered in the form of intramuscular atropine sulfate $(0.04 \mathrm{mg} / \mathrm{kg}$ body weight) and anesthetized with Xylazine (1 $\mathrm{mg} / \mathrm{kg}$ body weight) and ketamine (5 $\mathrm{mg} / \mathrm{kg}$ body weight) intramuscularly. Induction and maintenance involved the intravenous infusion of a xylazine and ketamine hydrochloride combination (1 and 5 $\mathrm{mg} / \mathrm{kg}-1$, respectively). During the entire operative period, normal saline was intravenously infused. After exposing the abdomen by laparotomy, the uterine and ovarian blood vessels were properly secured and the ovaries, uterine horns and uterus were completely removed(Fig.4). The gross examination revealed voluminous uterine horns (Fig.3) containing abundant sanguinepurulent fluid (Fig.5). The abdominal wall was closed with Vicryl No.1 according to a standard procedure. Finally, the skin was sutured using simple interrupted sutures with Silk. The wound was then disinfected with an antiseptic solution and protected with an adhesive dressing. Postoperatively, the animal was fed with moist food and maintained on daily parenteral antibiotics for 7 days. Sutures were removed on the $14^{\text {th }}$ postoperative day. No serious postoperative problems were observed in either anesthetic recovery or wound healing.

During the initial luteal phase, the increased progesterone concentration overwhelms cellular immunity (Sugiura et al., 2004). Estradiol causes cervical dilation during estrous and therefore allows bacteria that are part of the normal flora of the vagina (especially E. coli and Streptococcus spp.) to ascend into the uterus. The combination of reduced local immunity and favorable uterine conditions allows bacterial colonization and proliferation of these pathogens. It has been reported that inoculation of $E$. coli into the uterus on days 11 to 20 and 20 to 30 after the luteinizing hormone peak caused canine pyometra because at that time the uterus is 
most susceptible to infection (Smith, 2006). Subacute endometritis followed by $\mathrm{CEH}$ is believed to cause pyometra. Endometrial hyperplasia is the result of cystic deformation of endometrial glands and stromal proliferation of fibroblasts with inflammatory reaction (De Bosschere et al., 2001). However, the $\mathrm{CEH}$ pyometra complex also develops as a consequence of an abnormal response of the uterus to repeated progestational stimulation during the luteal phase of the estrous cycle (Feldman and Nelson, 2004). CEH is also associated with mucometra; it results from endometrial thickening with the accumulation of viscid uterine fluid caused by hyperplastic and hypertrophic endometrial glands. $\mathrm{CEH}$ is not associated with clinical signs unless the uterine content becomes infected; this is referred to as pyometra (Barton, 1992). Pyometra induces disturbed organ functions which are noted in the hematological and blood biochemical examinations. Typically there is leucocytosis, with neutrophilia and left shift in the differential white blood cell count (Børresen, 1980). Neutrophilia was the characteristic findingsin the present report which is in covenant with the findings of Mahesh et al., (2014). OHE is usually the recommended treatment for pyometra associated with $\mathrm{CEH}$ in bitches. Pyometra is best managed either by medical or hormonal therapy (prostaglandins) in patients not fit for surgery. However, adverse side effects ranging from simple allergy to anaphylactic reaction were reported after prostaglandin therapy by several researchers. Hence, Prostaglandins were not administered to the patient, seeing the severity of the case at the time of presentation to the clinic. In pyometra, ovariohysterectomy is always more complicated and carries a higher risk than routine spaying because of infection. This justifies the use of fluid therapy and a corticosteroid to stabilize the patient. Breeding bitches with a history of pyometra should be mated on the cycle following treatment using appropriate antibiotic therapy and surgical insemination to minimize contamination of the uterus. The interval between estrous cycles is usually shortened (4 - 6 weeks) following medical treatment because of the shortening of the luteal phase(progesterone secretion) resulting from prostaglandin therapy. Bitches treated medically will be predisposed to recurrence on subsequent cycles, so should be spayed as soon as their reproductive careers are concluded (Baithalu et al., 2010). Mated bitches must be monitored carefully after breeding for any signs of recurrence of the pyometra before and after the diagnosis of pregnancy. Pyometra and pregnancy can occur simultaneously. Approximately $30-$ $50 \%$ of bitches medically treated for pyometra can be successfully bred on subsequent cycles. The prognosis depends on the amount of damage to the endometrium. This is dependent on the amount ofpathology in the uterus, the length of time the pyometra was present before diagnosis, the response to treatment and the incidence of relapse. Prevention of pyometra is difficult because of the normal aging changes in the uterus due to progesterone dominance during estrous. The greater the number of the estrous cycle the greater the chances of pyometra occurrence. Intact bitches with short inter estrous interval and aged bitches are more predisposed topyometra because of the number of times the endometrium is exposed to progesterone production. The changes that lead to pyometra are normal aging changes in the uterus so most intact bitches if they were to live long enough, would eventually develop pyometra. For this reason, it is recommended that any bitch not being actively used for breeding or planned future breeding should be spayed before six months of age to prevent the occurrence of this disease (Foster and Smith, 20006). In the present case, voluminous pus was present in the uterus, so 
ovariohysterectomy was considered a judicious treatment for pyometra. A case of

surgical management of pyometra has been reported and discussed here.

Table.1 Serum and blood parameters with their significance in differentiating disease diagnosis

\begin{tabular}{|c|c|c|c|}
\hline Parameters & Healthy dog values & $\begin{array}{l}\text { Values in Pyometra } \\
\text { affected bitch }\end{array}$ & Significance \\
\hline Haemoglobin (g/dL) & $11.9-18.9$ & 11.9 & Within the normal range \\
\hline $\operatorname{PCV}(\%)$ & $35-57$ & 37 & Within the normal range \\
\hline $\operatorname{TLC}\left(\times 10^{3} / \mu \mathrm{L}\right)$ & $5.0-14.1$ & 6.9 & Within the normal range \\
\hline Neutrophils (\%) & $58-85$ & 95 & Relative Neutrophilia \\
\hline Lymphocytes (\%) & $8-21$ & 4 & Within the normal range \\
\hline Monocytes (\%) & $2-10$ & 01 & Within the normal range \\
\hline AST (IU/L) & $5-55$ & 29.9 & Within the normal range \\
\hline ALT (IU/L) & $10-109$ & 59.6 & Within the normal range \\
\hline Urea (mg/dl) & $8-28$ & 21.2 & Within the normal range \\
\hline Creatinine (mg/dl) & $0.1-2$ & 0.67 & Within the normal range \\
\hline
\end{tabular}
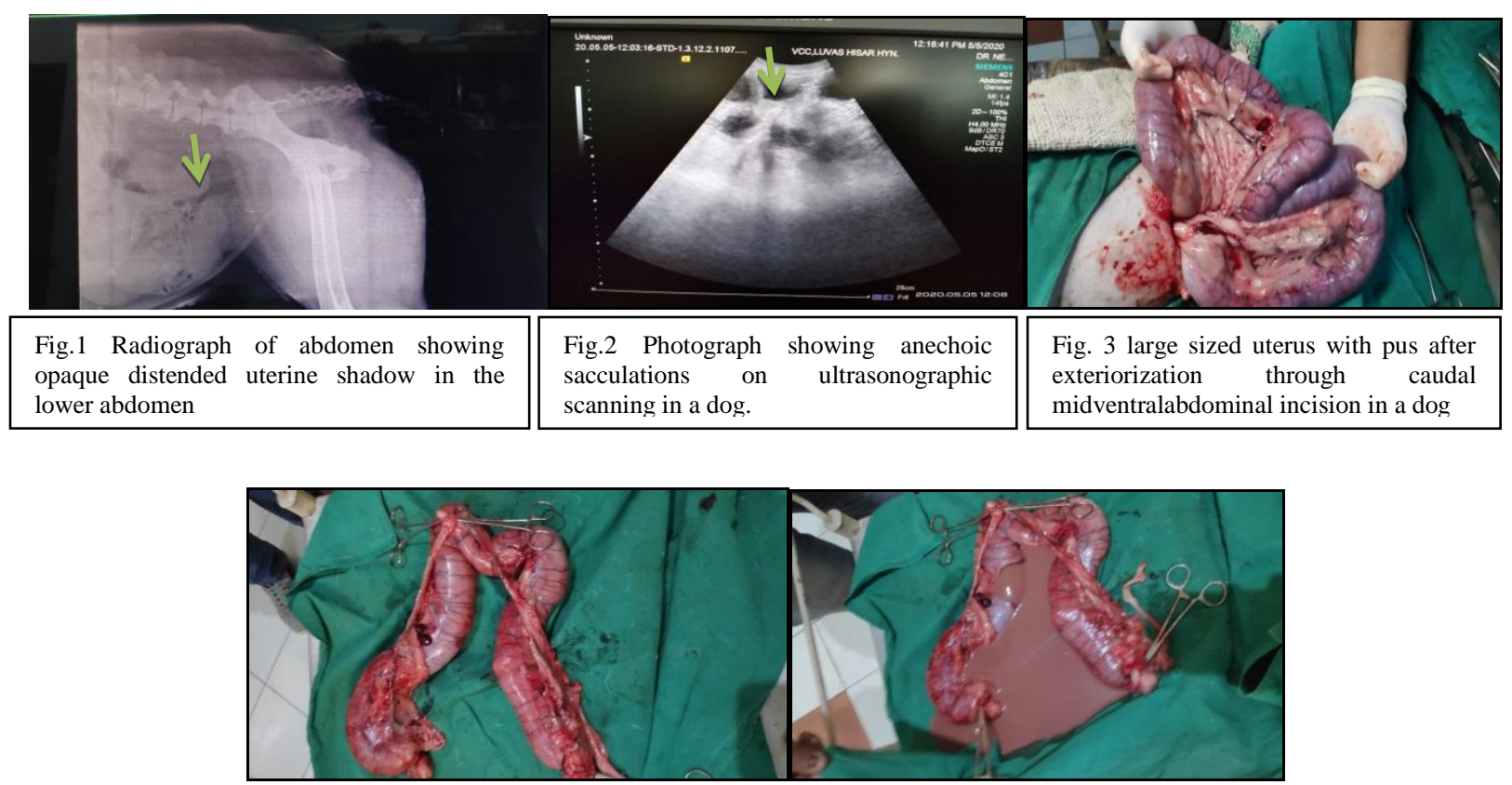

Fig.4 Photograph showing large sized uterus with pus after excision

Fig.5 Uterine horns containing abundant sanguine-purulent fluid 


\section{References}

Barton, C. (1992). Diseases of the UterusCystic Endometrial Hyperplasia/ Pyometra Complex. In: Morgan, R.V. (Eds). Handbook of Small Animal Practice. $2{ }^{\text {nd }}$ Edn. Churchill Livingstone, New York, USA. pp. 655-658

Børresen, B. (1980). Pyometra in the dog - a pathophysiological investigation. IV. Functional derangement of extragenital organs. Nordic veterinary medicine. 32, $255-268$.

Chotimanukul, S. and Sirivaidyapong, S. (2010).The relationship of canine vaginal and uterine bacterial species in closed cervix and opened-cervix pyometra. Proceedings of 13th Association of Institutions for Tropical Veterinary Medicine, Bangkok, Thailand. 184-186 Pp.

De Bosschere, H., Ducatelle, R., Vermeirsch, H., Van-Den Broeck, W. and Coryn, M. (2001). Cystic endometrial hyperplasiapyometra complex in the bitch: Should the two entities disconnected. Theriogenology. 55, 1509- 1519.

Feldman, E.C. and Nelson, R.W. (2004). Cystic Endometrial Hyperplasia/ Pyometra Complex in Canine and Feline Endocrinology and Reproduction. In: Kersey, R. and D. LeMelledo (Eds.). Canine and Feline Endocrinology and Reproduction. $3^{\text {rd }}$ ed. W.B. Saunders Company, USA, pp. $847-860$.

Hagman, R. and Greko, C. (2005). Antimicrobial resistance in Escherichia coli isolated from bitches with pyometra and from urine samples from other dogs. Veterinary Record. 157, 193-196

Brain, L.H. and Jeff, D. (May, 2012).Canine Pyometra: Early recognition and diagnosis. DVM360. https://www.dvm360.com/view/caninepyometra-early-recognition-anddiagnosis

Mahesh, R., Devi Prasad, V., Devarathnam, J., Sumiran, N., Kamalakar, G. and Suresh Kumar, R.V. (2014). Successful Management of a Critical Case of Pyometra in a Bitch. A Case Report. Research Journal of Animal, Veterinary and Fishery Sciences, 2(8): 21-23.

Hagman, R. (2000). New aspects of canine pyometra. Ph.D. Thesis, The Swedish University of Agricultural Sciences, Uppsala, Sweden.

Baithalu, R.K., Maharana, B.R., Sarangi, C. and Samal, L. (2010). Canine pyometra . Veterinary world. 3(3), 340-342.

Foster and Smith. (2006). Pyometra and uterus infections in dogs.

Shiju, SM., Ganesh, R., Arunprasad, A. and Kumar, RS. (2011): Incidence of pyometra in bitches - A survey of 278 cases. Tamilnadu Journal of Veterinary and Animal Sciences. 7, 252-253.

Smith, F.O. 2006. Canine pyometra. Theriogenology66. 610-612.

Sugiura, K., Nishikawa, M., Ishiguro, K., Tajima, T. and Inaba, M. (2004). Effect of ovarian hormones on periodical changes in immune resistance associated with estrous cycle in the beagle bitch. Immunobiology. 209, 619627.

\section{How to cite this article:}

Gyan Singh, Amitkumar, Neeraj Arora and Arjun, V. 2020. Successful Management of Pyometra in a Labrador Retriever A Clinical Case Report. Int.J.Curr.Microbiol.App.Sci. 9(10): 3823-3827. doi: https://doi.org/10.20546/ijcmas.2020.910.439 